
ISSN: 2027-4297

reciaeditor@unisucre.edu

Universidad de Sucre

Revista Colombiana de Ciencia Animal Colombia

\title{
Importância da vitamina D na nutrição de suínos
}

The importance of the vitamin D in pigs nutrition

Trautenmüller H, Faria ABB, Martins JS, Santos GB, LIMA AS. Importância da vitamina D na nutrição de suínos. Rev Colombiana Cienc Anim. Recia. 2019; 11(2):Articulo692. DOI: https://doi. org/10.24188/recia.v11.n1.2019.692

Universidad de Sucre, Colombia

Los autores permiten a RECIA reimprimir el material publicado en él. En caso de que un autor quiera traducir o usar una publicación parcial o completa de nuestro Diario, el autor debe obtener un permiso por escrito del editor de la revista.

Revista Colombiana de Ciencia Animal - RECIA está distribuido bajo una Licencia Creative Commons Atribución-CompartirIgual 4.0 Internacional. 


\title{
Importância da vitamina D na nutrição de suínos
}

\author{
The importance of the vitamin D in pigs nutrition
}

Heloíse Trautenmüller. M.Sc.

DOI: https://doi.org/10.24188/recia.v11.n2.2019.692

helotmuller@gmail.com

https://orcid.org/0000-0002-9546-892X

Universidade Estadual do Oeste do Paraná - UNIOESTE.

Departamento de Zootecnia, Marechal Cândido Rondon, PR,

Brasil.

Adriana Bulcão Bock de Faria. Lic.

adrianabulcao@outlook.com

https://orcid.org/0000-0002-2384-0120

Universidade Estadual do Oeste do Paraná - UNIOESTE.

Departamento de Zootecnia, Marechal Cândido Rondon, PR,

Brasil.

Juliana Stocco Martins. M.Sc.

justocc01993@hotmail.com

https://orcid.org/0000-0002-7525-1205

Universidade Estadual do Oeste do Paraná - UNIOESTE.

Departamento de Zootecnia, Marechal Cândido Rondon, PR,

Brasil.

Gleicianny De Brito Santos. M.Sc.

gleiciannyzoo@gmail.com

https://orcid.org/0000-0003-3867-6623

Universidade Federal da Bahia - UFBA, Departamento de Zootecnia, Salvador, BA, Brasil.

Arlene Dos Santos Lima. M.Sc.

arlene.zootecnia@gmail.com

https://orcid.org/0000-0002-1457-6129

Universidade Federal de Sergipe - UFSE, Departamento de

Zootecnia, São Cristóvão, SE, Brasil.

Recepción: 16 Enero 2019

Aprobación: 30 Septiembre 2019

Publicación: 08 Octubre 2019

\section{RESUMO}

A importância da vitamina D na nutrição de suínos, em especial a sua relevância no crescimento e desenvolvimento ósseo. À medida que se intensificou a criação animal, mudanças na estrutura das instalações foram necessárias para se adaptar ao sistema, portanto, o ambiente que antes era aberto hoje apresenta instalações fechadas com telhado, o qual reduziu drasticamente o contato dos animais com o sol. Em consequência disso, os animais passaram a ser suplementados com a vitamina D na forma sintética para compensar a falta dos raios solares. Sendo assim, esta vitamina se tornou um elemento essencial nas rações de animais confinados.

Palavras-chave: alimentação animal, desenvolvimento ósseo, suinocultura, cálcio. 


\begin{abstract}
This article aims to present the importance of vitamin D in pig nutrition, especially its relevance in bone growth and development, in the form of a literature review. As animal husbandry intensified, changes in the structure of the facilities were necessary to adapt to the system, so the environment that was once open, today has closed, with roof facilities, which has drastically reduced the animals contact with the sun. As a result, the animals were then supplemented with vitamin $\mathrm{D}$ in synthetic form to compensate for the lack of sunlight exposure. Therefore, this vitamin has become an essential element in confined animal feed.
\end{abstract}

Keywords: animal feed, bone development, calcium, swine.

\title{
INTRODUÇÃo
}

A importância da vitamina D foi reconhecida nas últimas décadas e despertou o interesse da comunidade científica, com ênfase na saúde humana, demonstrando que uma parcela significativa da população apresenta deficiência da vitamina D. Estudos em suínos utilizando a vitamina D são escassos e mais pesquisas são necessárias para avaliar o comportamento da vitamina no organismo desta espécie (1).

A vitamina D é dificilmente encontrada em quantidades significativas nos alimentos, com algumas exceções, como no caso de alguns peixes, cogumelos e plantas. Do ponto de vista evolucionário, a vitamina D provinda de alimentos não era necessária, pois ao longo de milhões de anos, os humanos e muitas espécies animais desenvolveram um mecanismo fotossintético na pele capaz de produzir vitamina D. Assim sendo, a pele faz parte do sistema endócrino da vitamina D (2).

A vitamina D é uma vitamina lipossolúvel conhecida popularmente como a "vitamina do sol", este título se refere à capacidade da vitamina $\mathrm{D}$ em se originar de conversões realizadas na pele através dos raios solares. Devido a isto, tanto animais como seres humanos, que passam os dias em locais fechados e se alimentam com baixas quantidades de vitamina $\mathrm{D}$, tendem a apresentar deficiência desta vitamina. Animais expostos à radiação solar apresentam maior capacidade de conversão dos metabólitos em vitamina D e raramente manifestam esta deficiência (3).

Sabe-se que a deficiência de vitamina D, cálcio e outros minerais está associada com a incidência de diversos distúrbios articulares nos suínos, como a osteocondrose. As causas para estes problemas locomotores ainda não estão bem esclarecidos, porém, foi reconhecido que existe um fator genético para a osteocondrose. 0 rápido crescimento dos animais e a redução da espessura de gordura subcutânea tendem a agravar estes problemas $(4,5)$. Estes problemas locomotores são responsáveis por uma tremenda perda econômica na indústria suína, principalmente no que diz respeito a fraqueza das pernas, e cerca de 20 a 50\% dos suínos machos são descartados para a reprodução (6).

A função mais conhecida e estudada da vitamina D é a sua atividade no metabolismo de cálcio e fósforo, com a finalidade de buscar a homeostase mineral também participa da formação do tecido ósseo. Recentemente outras funções da vitamina D foram reconhecidas através da descoberta de receptores da vitamina em outros órgãos, como no sistema imune $(7,8)$.

\section{VITAMINAS E MINERAIS}

As vitaminas podem ser classificadas de acordo com a sua solubilidade, esta classificação é a mais comumente utilizada na literatura e as divide em duas classes, as lipossolúveis e as hidrossolúveis. As vitaminas lipossolúveis são aquelas que se dissolvem em lipídeos e outros solventes orgânicos, esta classe compreende as vitaminas A, D, E e K. As vitaminas hidrossolúveis são solubilizadas em água, sendo elas o ácido fólico, ácido ascórbico, cianocobalamina, piridoxina, tiamina, niacina, riboflavina, biotina e ácido pantotênico.

O armazenamento das vitaminas pode variar de acordo com as suas propriedades físicas e químicas. As vitaminas lipossolúveis tendem a acumular-se em tecidos lipídicos, como a gordura e o fígado, em contrapartida as vitaminas hidrossolúveis são rapidamente excretadas e pouco armazenadas, com exceção da vitamina B12 (cianocobalamina) que em circunstâncias normais pode ser armazenada no fígado (3). Assim como as demais vitaminas lipossolúveis, a vitamina D pode ser armazenada no organismo, portanto elevadas doses dessa vitamina podem gerar uma toxicidade devido a sua ação na hipercalcemia, podendo causar deposição de cálcio em órgãos (9). 
Algumas vitaminas podem ser biossintetizadas através de precursores encontrados no organismo, são elas: a vitamina D, proveniente do 7-dehidrocolesterol; a vitamina $\mathrm{C}$ proveniente da glicose e a niacina proveniente do triptofano. Entretanto esta biossíntese é limitada e depende de atividades metabólicas e catalíticas (3).

Diversas vitaminas necessitam de conversão metabólica para desempenhar suas devidas funções no organismo, são chamadas de pré-vitaminas e são consideradas inativas até o momento em que sua estrutura química é alterada ou ligada a outro metabólito, tornando-se ativas. As vitaminas que requerem ativação são: vitamina $\mathrm{A}$, vitamina $\mathrm{D}$, Vitamina $\mathrm{K}$, Vitamina B6, vitamina B12, tiamina, riboflavina, niacina, folato e ácido pantotênico (3).

As vitaminas lipossolúveis são excretadas via fezes, com exceção de alguns metabólitos ativos das vitaminas A e E que são solúveis em água. Em contraste, as vitaminas hidrossolúveis são geralmente excretadas na urina. 0 tipo de função metabólica das vitaminas depende da sua distribuição nos tecidos e nas células e da sua reação química, que pode ser direta ou indiretamente relacionada à sua estrutura química. As vitaminas desempenham cinco funções básicas no metabolismo, não sendo necessariamente mutuas, são elas: antioxidantes, hormônios, elementos de transcrição gênica, doadores e aceptores de $\mathrm{H}^{+} / e^{-}$, coenzimas (3).

\section{VITAMINA D}

Esta vitamina é encontrada na natureza sob duas formas, o ergocalciferol (vitamina $\mathrm{D}_{2}$ ) e o colecalciferol (vitamina $\mathrm{D}_{3}$ ), como pró-vitaminas em plantas e animais. O Ergosterol é o precursor do ergocalciferol e é encontrado em plantas, fungos, liquens, bolores e alguns invertebrados como minhocas e lesmas. A distribuição do ergocalciferol na natureza é muito mais limitado que o ergosterol, por exemplo, fenos de gramíneas e alfafa só apresentam vitamina $\mathrm{D}_{2}$ depois do corte e exposição à luz solar para a secagem (3).

O colecalciferol é facilmente encontrado nos animais, seu precursor, o 7-dehidrocolesterol é um metabólito comum (Figura 1). A presença da vitamina $\mathrm{D}_{3}$ depende do seu consumo na alimentação e da exposição à luz solar. Poucos alimentos contêm esta forma de vitamina, como exemplo o fígado de peixe e óleos. Notavelmente, algumas plantas apresentam os metabólitos do colecalciferol que são solúveis em água, o 25-hidroxicolecalciferol $\left(25(\mathrm{OH}) \mathrm{D}_{3}\right)$ e o 1,25-dihidroxicolecalciferol $\left(1,25(\mathrm{OH})_{2} \mathrm{D}_{3}\right)$, essas exceções de plantas são das espécies Solanum glaucophyllum, Solanum malacoxylon, Cestrum Diurnum e Trisetum flavescens (3).

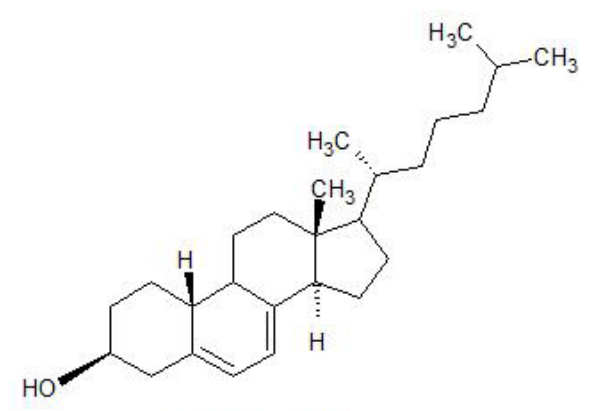

7-dehidrocolesterol<smiles>C=C1CC[C@H](O)C/C1=C/C=C1\CCC[C@@]2(C)C([C@H](C)CCCC(C)C)CC[C@@H]12</smiles>

Colecalciferol (Vitamina $\mathrm{D}_{3}$ )<smiles>C=C1CC[C@H](O)CC1=C(C)C=C1CCC[C@@]2(C)[C@@H]1CC[C@H]2[C@@H](C)CCCC(C)(C)O</smiles>

25-hidroxicolecalciferol

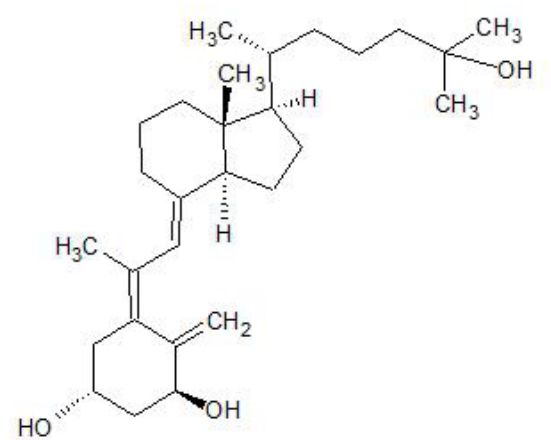

1,25-dihidroxicolecalciferol

Figura 1. Estruturas químicas do precursor da vitamina D3 (7-dehidrocolesterol) e das principais formas encontradas no organismo animal 
A vitamina D pertence a um grupo de esteroides com funções semelhantes às dos hormônios. Para que ocorra a ativação desta vitamina são necessárias duas conversões metabólicas, a primeira ocorre no fígado e a segunda nos rins, formando a $1,25(\mathrm{OH})_{2} \mathrm{D}_{3}$, também chamado de calcitriol (9). A forma ativa da vitamina $\mathrm{D}$ é considerada um hormônio esteroide, pois suas funções se assemelham a estes hormônios, quando ligados aos receptores de vitamina D (VDR) e sua estrutura molecular é semelhante a hormônios como estradiol, cortisol e aldosterona, pois possuem um anel ciclopentanoperidrofenantreno (10).

O sistema endocrinológico da vitamina D é considerado um fascinante eixo metabólico, esse sistema é formado pelos metabólitos da vitamina D, sua proteína de transporte DBP ( $D$ binding protein), seu receptor VDR e as enzimas que participam das reações de ativação e inativação (1).

Em um estudo realizado (11) foram avaliados animais confinados comparados a animais expostos aos raios solares, os autores não encontraram diferenças no ganho de peso dos animais, porém a concentração de vitamina $\mathrm{D}$ na forma $25(\mathrm{OH}) \mathrm{D}_{3}$ foi superior nos animais expostos ao sol, com o pico de concentração em 24h seguida de redução, entretanto permaneceu elevada durante três semanas após a exposição ao sol. Nas 12 semanas seguintes a concentração de 25(OH) $\mathrm{D}_{3}$ reduziu a mesma medida que seria sustentada apenas pela dieta. Apesar da quantidade de calcidiol estar aumentada, a expressão da enzima 1-hidroxilase não foi alterada, demonstrando um controle rigoroso na conversão da forma ativa, portando mesmo havendo uma maior concentração da $25(\mathrm{OH}) \mathrm{D}_{3}$, isto não quer dizer que toda ela será convertida para sua forma hormonal, mas sim haverá um armazenamento da vitamina.

De modo geral, a função principal da vitamina D é a manutenção dos níveis plasmáticos de cálcio no organismo, para isso são utilizados três processos, a absorção do cálcio pelo intestino, a redução da excreção renal e a reabsorção óssea (9).

\section{CÁLCIO E FóSFORO}

A maior parte do cálcio encontrado no organismo está depositado nos ossos e nos dentes, apenas uma pequena quantia está circulante no plasma, está quantidade pode ser dividida em três frações cálcio ionizado (50\%), cálcio ligado às proteínas (40\%) e cálcio complexado com citrato e fosfato (10\%). 0 cálcio ionizado e complexado pode atravessar a membrana plasmática, a maior parte do cálcio ligado a uma proteína está ligado à albumina e uma fração menor está ligada às globulinas (12).

A concentração de cálcio no soro da maioria das espécies é de $10 \mathrm{mg} \mathrm{dL}^{-1}$, o processo de homeostasia responde ao decréscimo desse valor modulando a entrada e saída deste mineral de três maneiras, via intestinos, rins e ossos. Por exemplo, durante a hipocalcemia, o PTH é liberado e age sobre os rins de forma a estimular a conversão da $25(\mathrm{OH}) \mathrm{D}_{3}$ em $1,25(\mathrm{OH})_{2} \mathrm{D}_{3}$, que consequentemente age no intestino pelo aumento da função da calbindina e pelo aumento da ressorção óssea mobilizando cálcio e fosfato. Em condições de hipercalcemina, a calcitonina é secretada pela tireóide, e apresenta a função de suprimir a desmineralização óssea e aumentar a excreção renal de cálcio e fosfato, também ocorre a inibição da formação da $1,25(\mathrm{OH})_{2} \mathrm{D}_{3}$ e aumento da formação da $24,25(\mathrm{OH})_{2} \mathrm{D}_{3}$. (3).

O cálcio desempenha múltiplas funções fisiológicas no organismo. $0 \mathrm{Ca}^{2+}$ é um mensageiro intracelular essencial e cofator de várias enzimas, ele também possui funções extracelulares como a coagulação do sangue e a modulação da excitabilidade neuromuscular. Portanto a concentração de cálcio é importante para o controle de diversas funções. Quando esta concentração é muito reduzida, reduz o limiar de voltagem para a descarga do potencial de ação, resultando em hiperexcitabilidade neuromuscular que pode ocasionar dormência e formigamento ou cãibras musculares (12).

Os segmentos do trato gastrointestinal como estômago, ceco e cólon apresentam menor relevância na absorção do cálcio, mais de $90 \%$ da absorção de cálcio diário ocorre no intestino delgado, mais precisamente nas partes proximais duodeno e jejuno (13). A quantidade de cálcio que pode ser realmente absorvida no trato gastrointestinal dos animais varia de acordo com o estado fisiológico. A eficiência da absorção diminui com o avanço da idade, animais jovens absorvem cálcio de uma forma mais eficaz, a medida que o animal envelhece ocorre uma redução nos receptores de vitamina D no trato intestinal, o que reduz a capacidade de responder à 1,25(OH) ${ }_{2} \mathrm{D}_{3}$ (15). Esta afirmação foi comprovada por autores (14) que avaliaram a inclusão da $25(\mathrm{OH}) \mathrm{D}_{3}$ na dieta de suínos de 3 a 21 semanas de idade e constataram o decréscimo de cálcio no plasma conforme o aumento da idade dos animais.

O cálcio pode ser absorvido de forma transcelular (ativa) no duodeno e no início do jejuno e de forma paracelular (passiva) em todo o intestino. Na absorção transcelular ocorre a captação do cálcio no lúmen intestinal para a borda em escova e absorção por mecanismos envolvendo canais de cálcio ou um transportador de membrana (CaT1), o transporte dentro do enterócito envolve a calbidina, que transporta mais de $90 \%$ do fluxo de cálcio transcelular, o cálcio atinge a 
circulação sanguínea por meio de um mecanismo termodinâmico e um potencial elétrico positivo, facilitado por uma ATPase. A absorção ativa é extremamente importante quando as dietas apresentam poucas quantidades de $\mathrm{Ca}^{2+}$, esta forma de transporte é mediada pela $1,25(\mathrm{OH})_{2} \mathrm{D}_{3}$ que interage com receptores localizados no epitélio intestinal e realiza a transcrição das proteínas transportadoras de $\mathrm{Ca}^{2+}$. A absorção paracelular de $\mathrm{Ca}^{2+}$ entre as células epiteliais ocorre sempre que o cálcio ionizado nos fluidos digestivos exceder a $6 \mathrm{mM}$, que ocorre geralmente quando animais jovens bebem leite, e até $50 \%$ do cálcio pode ser absorvido desta maneira $(3,15)$.

No interior da célula epitelial tubular dos rins, o $\mathrm{Ca}^{2+}$ se liga à calbindina e se difunde pela membrana basolateral. $\mathrm{A}$ calbindina é uma proteína de ligação do cálcio e dependente de vitamina D, ela é encontrada no citosol das células que revestem a parte distal do néfron. Esta proteína de ligação facilita a difusão de $\mathrm{Ca}^{2+}$ no citosol a partir dos locais de influxo apical para os de efluxo basolateral. 0 transporte do cálcio da célula para o espaço intersticial é mediado por um trocador $\mathrm{Na}^{+} / \mathrm{Ca}^{2+}$ e por uma cálcio ATPase. No intestino ocorre de forma semelhante (12).

Depois do cálcio, o fósforo é o mineral em maior abundância nos ossos. A maior parte do fósforo encontrado no organismo está complexado com o oxigênio formando o ânion fosfato. 0 fosfato é componente de fosfolipídeos, fosfoproteínas, ácidos nucleicos e de moléculas que transferem energia, como o ATP. Os níveis normais de fósforo plasmático nos mamíferos variam entre 4 a $8 \mathrm{mg} \mathrm{dL}^{-1}$. Cerca de 30\% do fosforo sanguíneo está na forma de fosfato inorgânico, o restante está incorporado em moléculas orgânicas. Quando há uma deficiência de cálcio, o PTH é liberado para agir na reabsorção óssea, porém outra função do PTH é aumentar a excreção renal de fósforo, devido a isso, animais hipocalcêmicos tem grandes chances de se apresentarem hipofosfatêmicos também (15).

Assim como a $1,25(\mathrm{OH})_{2} \mathrm{D}_{3}$ regula a absorção intestinal de $\mathrm{Ca}^{2+}$, ela também regula a absorção de fósforo no intestino delgado, que ocorre por transporte ativo, e modula o aumento do número de sítios carreadores dependentes de sódiofosfato na membrana da mucosa. Portanto, as concentrações fósforo também determinam a conversão $25(\mathrm{OH}) \mathrm{D}_{3}$, sendo esta aumentada quando há deficiência do mineral. (15). Isto foi confirmado por um trabalho em que encontraram uma maior concentração de $1,25(\mathrm{OH})_{2} \mathrm{D}_{3}$ no plasma de leitões recebendo uma dieta deficiente em fósforo, demonstrando que a conversão da $25(\mathrm{OH}) \mathrm{D}_{3}$ foi maior nestes animais, com a finalidade de regular a absorção de fósforo (16).

\section{ABSORÇÃO E TRANSPORTE DA VITAMINA D}

A absorção da vitamina D ocorre no intestino delgado por difusão passiva insaturada e é dependente do processo de solubilização micelar e da presença dos sais biliares. A absorção ocorre mais rapidamente no duodeno e jejuno, porém, devido ao transito intestinal ser mais lento no íleo, este é o local com a maior absorção (3).

Do mesmo modo como ocorre com outras substâncias hidrofóbicas em mamíferos, a vitamina D é absorvida por difusão passiva dependente das micelas, e cerca de $90 \%$ do total absorvido é transportado pela circulação linfática associada com os quilomicrons. A eficiência deste transporte de absorção configura em torno de 50\%. Os quilomicrons são transportados ao fígado, onde ocorre a degradação da sua estrutura e liberação da vitamina $\mathrm{D}$, que é ligada à proteína albumina para ser transportada no sangue (3).

A principal forma de transporte da vitamina D é ligada a uma glicoproteína do soro chamada “DBP” (D binding protein). Esta proteína é sintetizada no fígado e apresenta meia vida biológica de 2.5 dias. A quantidade de DBP no organismo é excessivamente maior do que a quantidade de $25(\mathrm{OH}) \mathrm{D}_{3}$, este fator se deve a uma proteção contra a intoxicação causada pela vitamina D livre (17).

A forma mais abundante da vitamina $\mathrm{D}$, a $25(\mathrm{OH}) \mathrm{D}_{3}$ apresenta alta afinidade com a $\mathrm{DBP}$, mais de $80 \%$ da vitamina $\mathrm{D}$ é transportada por esta proteína, uma quantidade menor é ligada a albumina, porém com baixa afinidade. Estas duas proteínas de transporte também podem carregar a forma ativa da vitamina D, porém apresentam menor afinidade. Nos rins, a rota de entrada da vitamina D é através da megalina, a proteína 2 relacionada à lipoproteína de baixa afinidade (lowdensity lipoprotein-related protein 2), encontrada nas células epiteliais, esta proteína é capaz de realizar uma endocitose da vitamina D e suas proteínas carreadoras são degradadas e os metabólitos liberados. Em tecidos sem a megalina, os metabólitos da vitamina D entram por difusão nas suas formas livres (18).

\section{BIOSSÍNTESE E METABOLISMO DA VITAMINA D}

A vitamina $D_{3}$ é formada nos animais pela ação da luz ultravioleta (295-300 nm) sobre o esteroide 7-dehidrocolesterol na epiderme da pele. A reação de ativação depende da absorção da luz pelo 5,7-dieno do anel beta do núcleo esteroide da 
célula, causando abertura e isomerização para uma forma que é mais estável. Essa reação físico-química converte apenas 5 a 15\% do 7-dehidrocolesterol disponível. Essa eficiência depende do tipo de pele, do ambiente, da espécie animal, da hora do dia, da estação do ano e da latitude (3).

Em ratos a reação de fotólise ocorre na parte mais superficial da pele, o estrato córneo, já em humanos, ocorre mais profundamente, na camada de malpighi, podendo ocorrer perda dos raios UV e em pessoas com pele mais escura, a melanina impede a passagem dos raios, ocorrendo menos conversão (3).

A reação que ocorre na epiderme promove a fotólise da ligação entre os carbonos 9 e 10 do anel $\beta$ do ciclo pentanoperidrofenantreno, cuja molécula apresenta um dos anéis rompido. Essa nova substância é termoinstável, chamada de pré-vitamina, sofre uma reação de isomerização provocada pelo calor e se torna uma molécula mais estável, o chamado colecalciferol. A vitamina $\mathrm{D}_{3}$ é secretada para o meio extracelular e para a corrente sanguínea através da energia estérica promovida pela sua conformação tridimensional (1).

O primeiro passo da ativação metabólica da vitamina D é uma hidroxilação que ocorre no fígado (Figura 2) sobre o carbono C-25 do colecalciferol para formar a $25(\mathrm{OH}) \mathrm{D}_{3}$, que é a principal forma circulante da vitamina. Essa hidroxilação é mediada pela enzima 25-hidroxilase, uma enzima microssomal da superfamília do citocromo P450 denominada CYP2R1. Existem dois mecanismos para que ela ocorra, um é através da enzima associada ao reticulo endoplasmático e possui baixa afinidade e alta capacidade, e o outro é pela enzima localizada na mitocôndria e possui alta afinidade e baixa capacidade $(3,19)$.

A vitamina $\mathrm{D}$ é catabolizada de diferentes formas, que podem ser a clivagem oxidativa da cadeia lateral; a hidroxilação da $1,25(\mathrm{OH})_{2} \mathrm{D}_{3}$ que forma a $1,24,25(\mathrm{OH})_{3} \mathrm{D}_{3}$ e a $1,25,26(\mathrm{OH})_{3} \mathrm{D}_{3}$; e a formação da $1,25(\mathrm{OH})_{2} \mathrm{D}_{3}-23,26$-lactona. Quando há um excesso de metabolitos da vitamina D no organismo há um aumento na atividade da enzima 24-hidroxilase (CYP24A1), cuja maior concentração é encontrada na mitocôndria renal, e podem ser formandos tanto o $24,25(\mathrm{OH})_{2} \mathrm{D}_{3}$ quanto o $1,24,25(\mathrm{OH})_{3} \mathrm{D}_{3}$, a atividade desta enzima é aumentada em casos de hipercalcemia e hiperfosfatemia (3).

A $25(\mathrm{OH}) \mathrm{D}_{3}$ é liberada no plasma ligada à DBP e vai aos rins para sofrer uma segunda hidroxilação, desta vez no C-1 do anel A, formando a $1,25(\mathrm{OH})_{2} \mathrm{D}_{3}$. Essa hidroxilação é catalizada pela enzima 1-hidroxilase (CYP27B1), e ocorre primariamente na região cortical da mitocôndria renal, mas também pode ser encontrada em tecidos extra renais, como nos ossos, fígado e placenta. A 1-hidroxilase usa $\mathrm{NADPH}_{2}$ como doador de elétrons e possui três proteínas constituintes: ferridoxina redutase, ferridoxina e citocromo P450 (CYP1a). (3).

O receptor da $1,25(\mathrm{OH})_{2} \mathrm{D}_{3}$, VDR (vitamin D receptor), é uma proteína sulfidril está presente no núcleo celular dos tecidos alvos (intestinos, rins e ossos) para exercer suas funções clássicas e também em outros tecidos como placenta, tecido pancreático, paratireoide, células gastrointestinais endócrinas e algumas células do tecido cerebral, essa ligação entre o VDR e a $1,25(\mathrm{OH})_{2} \mathrm{D}_{3}$ causa uma mudança conformacional na proteína que aumenta a afinidade pelo DNA, o que sugere funções genômicas da vitamina D. Os receptores VDR quando ligados à vitamina D são transativadores essenciais para a transcrição de mRNA's para várias proteínas envolvidas no transporte de cálcio, matriz óssea e regulação do ciclo celular (3).

$\mathrm{O}$ VDR atua por meio de uma heterodimerização com uma das três isoformas do receptor retinóide X (RXR). A 1,25(OH) ${ }_{2} \mathrm{D}_{3}$ se liga ao VDR causando uma mudança na sua conformação e forma um complexo hormônio-receptor, esse complexo é heterodimerizado com o RXR e o heterodímero $1,25(\mathrm{OH})_{2} \mathrm{D}_{3}$-VDR-RXR se liga a uma sequência específica do DNA nos seus genes-alvos, chamada de VDRE (vitamin D response element) (21)

A concentração de $1,25(\mathrm{OH})_{2} \mathrm{D}_{3}$, o paratormônio (PTH), a calcitonina, os níveis circulantes de cálcio e fosfato bem como outros hormônios são os diversos fatores que regulam o sistema endócrino da vitamina D. A atividade da enzima 25-hidroxilase é pouco regulada pela concentração hepática da vitamina D, com pouca ou nenhuma inibição pela 25(OH) $\mathrm{D}_{3}(3)$. Os efeitos fisiológicos do PTH consistem na elevação dos níveis plasmáticos de cálcio pelo aumento da reabsorção renal, pela mobilização do $\mathrm{Ca}^{2+}$ do osso e aumento da absorção intestinal. 0 PTH também aumenta a excreção renal de fosfato e aumenta a atividade da enzima $1 \alpha$-hidroxilase (12).

A DBP apresenta alta afinidade com a $25(\mathrm{OH}) \mathrm{D}_{3}$ e por isso $90 \%$ está ligada a ela, restando apenas $5 \%$ do total para se ligar aos demais metabólitos da vitamina D. Devido a esta característica há um acumulo maior da forma $25(\mathrm{OH}) \mathrm{D}_{3}$ no plasma, que usualmente é utilizada para mensurar a atividade da vitamina D (3). 


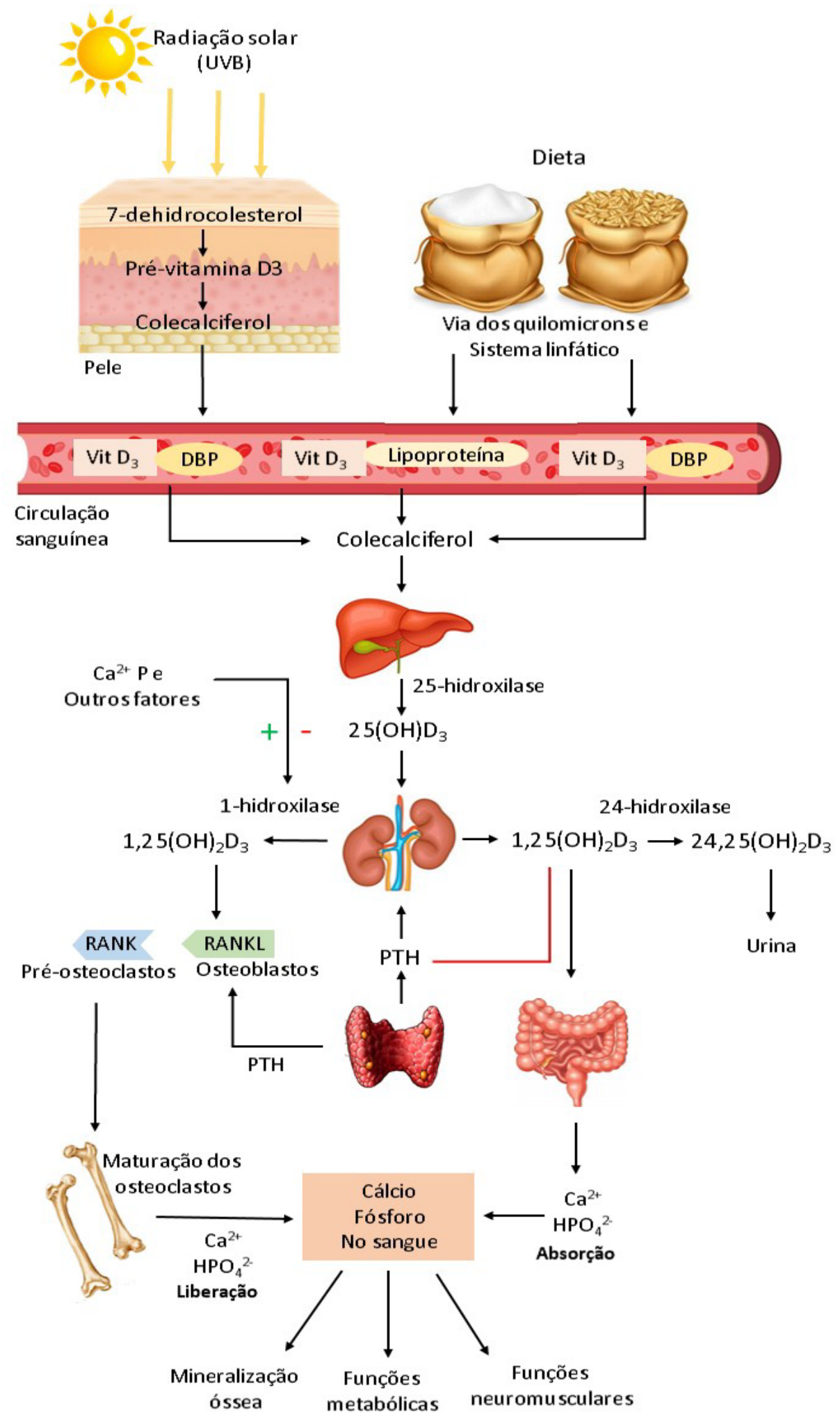

Figura 2. Metabolismo da vitamina D.

Fonte: Adaptado de Holick, 2006 (20).

\section{FUNÇõES METABÓLICAS DA VITAMINA D}

Para que a vitamina D exerça suas funções é necessário que ela esteja em sua forma biologicamente ativa, a 1,25(OH) $\mathrm{D}_{3}$. Essas funções podem ser divididas em genômicas e não genômicas. A forma ativa da vitamina D se liga ao seu receptor 
VDR no núcleo das células alvo, podendo se ligar também a receptores de outros hormônios esteroides que possuem a mesma sequência homóloga, como é o caso do hormônio da tireoide e ácido retinóico. Algumas sequencias específicas de pares de DNA chamadas de "vitamin D-responsive elements" (VDREs) são semelhantes aos mediadores das respostas do hormônio tireoidiano e acido retinóico, e a ligação entre 1,25(OH) ${ }_{2} \mathrm{D}_{3}$-VDR com um VDRE envolve um receptor X retinóide (RXR). A mudança conformacional que ocorre quando há ligação entre a 1,25(OH) ${ }_{2} \mathrm{D}_{3}$ e o VDR expõe domínios da proteína que são capazes de interagir aos VDREs. Tanto o VDR quando o RXR está presente na maioria das células, portanto, pode ser que a disponibilidade do ácido 9-cis-retinóico determine qual conjunto de genes será regulado pela $1,25(\mathrm{OH})_{2} \mathrm{D}_{3}(3)$.

Em torno de 50 genes são regulados pela vitamina D, incluindo genes associados ao metabolismo, diferenciação e proliferação celular, metabolismo energético, homeostasia mineral, sinalização hormonal, entre outros. 0 primeiro gene conhecido induzido pela $1,25(\mathrm{OH})_{2} \mathrm{D}_{3}$ foi o das calbindinas, anteriormente chamadas de "calcium-binding proteins", são amplamente encontradas no tecido do duodeno de mamíferos e possuem a função de carrear o cálcio pelo citosol do enterócito. Foram identificadas duas calbindinas, a calbindina- $\mathrm{D}_{9 \mathrm{k}^{\prime}}$, capaz de se ligar a dois átomos de Ca ${ }^{2+}$, e a calbindina$\mathrm{D}_{28 \mathrm{k}^{\prime}}$ que se liga a quatro átomos de $\mathrm{Ca}^{2+}(3)$.

Algumas das funções não genômicas incluem estimulação da síntese de fosfolipídios da membrana, níveis de GMPc e ativação dos canais de cálcio na membrana dos enterócitos. A função mais estudada e elucidada, e provavelmente a mais importante, é a homeostase do cálcio e fosfato. Outra função não genômica da $1,25(\mathrm{OH})_{2} \mathrm{D}_{3}$ é a reabsorção renal de cálcio e fosfato, este mecanismo ocorre no túbulo renal distal, e é maior para o fosfato do que para o cálcio, sendo que o cálcio também pode ser reabsorvido no túbulo proximal e na alça de Henle por um processo paracelular, e de forma semelhante ao que ocorre no intestino no processo transcelular (3).

\section{FORMAÇÃO E DESENVOLVIMENTO DO TECIDO ÓSSEO}

A cartilagem é um tipo especial de tecido conjuntivo muito importante no desenvolvimento embrionário, pois serve como modelo no qual o osso verdadeiro é formado mais tarde. A cartilagem também está presente nos animais adultos, principalmente nas articulações, reduzindo o impacto entre os ossos adjacentes (15). 0 tecido cartilaginoso é formado por células chamadas de condrócitos e abundante material extracelular, que constitui a matriz. As funções da cartilagem dependem da estrutura da matriz, que pode ser formada por colágeno ou colágeno mais elastina, associados com proteoglicanos (proteínas + glicosaminoglicanos), ácido hialurônico e outras glicoproteínas. Este tecido não apresenta vasos sanguíneos, sendo nutridos pelos capilares do tecido conjuntivo que o reveste ou do líquido sinovial no caso das cavidades articulares (22).

Existem três tipos de cartilagens: (1) a cartilagem hialina, cuja matriz contém delicadas fibrilas constituídas principalmente por colágeno tipo II, são encontradas nas extremidades ventrais das costelas, dentro dos anéis traqueais e na laringe, e nas superfícies articulares dos ossos. É a base para o crescimento dos ossos longos e compreende a placa de crescimento destes ossos nos animais jovens. (2) A cartilagem elástica, que contém pouca quantidade de colágeno tipo II e mais fibras elásticas, pode ser encontrada na orelha externa e epiglote. (3) A fibrocartilagem, constituída por fibras de colágeno tipo I, encontrada em muitos ligamentos do osso, dentro de discos intervertebrais e na sínfise do púbis $(15,22)$.

A $1,25(\mathrm{OH})_{2} \mathrm{D}_{3}$ atua diretamente nos condrócitos da placa de crescimento, que expressam a CYP27B1, a vitamina D ativa neste local apresenta funções autócrinas, como a diferenciação celular, a angiogênese e a osteoclastogenese (23).

São os ossos que dão a forma identificável ao corpo dos animais e protegem os órgãos do crânio, tórax, abdome e pélvis. Além disso, na cavidade medular dos ossos ocorre a formação de células sanguíneas e a região calcificada serve como depósito de vários minerais. A composição do osso com base no peso úmido é de aproximadamente $25 \%$ de água, 45\% de minerais e $30 \%$ de matéria orgânica, sendo que o cálcio constitui cerca de 37\% dos minerais e o fósforo 18,5\% (15).

Um osso longo possui três regiões distintas (Figura 3), as extremidades chamadas de epífises, a haste longa chamada de diáfise e nos animais em crescimento uma região denominada metáfise, formada por osso esponjoso transicional que se liga à placa epifisária. No interior da diáfise se encontra uma lacuna que dá origem à medula óssea, esta superfície interna do osso é chama de endósteo. 0 exterior das superfícies ósseas é coberto por uma camada de células que forma o chamado periósteo (15). 


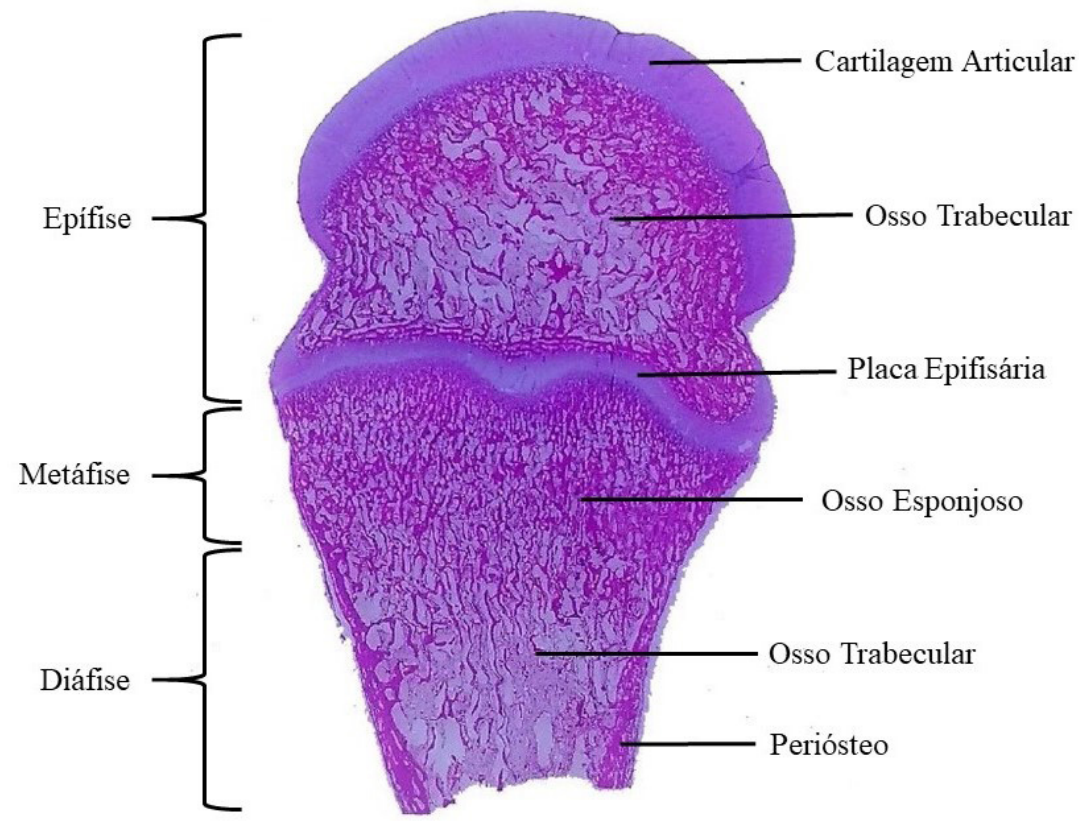

Figura 3. Fotografia de corte histológico de metatarso de suíno com aproximadamente 2,5 meses de idade representando a anatomia de um osso longo em crescimento (coloração eosina-hematoxilina).

Fonte: Arquivo Pessoal.

Existem três tipos de células envolvidas no desenvolvimento ósseo, são elas: os osteoblastos, os osteoclastos e os osteócitos. Os osteoblastos são as principais células envolvidas no processo de ossificação, sendo claramente observadas na formação do osso, o seu núcleo celular se localiza na extremidade da célula e o citoplasma é rico em reticulo endoplasmático rugoso, sendo a célula responsável pela síntese e secreção das proteínas que formarão a matriz orgânica do osso. Os osteoblastos quando capturados dentro da matriz orgânica formam os osteócitos, células maduras, são pequenas e achatadas que sofrem apoptose ou fagocitose durante a reabsorção óssea. Os osteoclastos são células grandes, multinucleadas, apresentam mobilidade podendo migrar para superfícies que estão em reabsorção, no seu citoplasma encontram-se numerosos lisossomos $(12,15)$.

Existem duas vias diferentes para a formação dos ossos, a ossificação intramembranosa e a ossificação endocondral. A ossificação intramembranosa ocorre nos ossos chatos do crânio, como o osso frontal, parietal, occipital e temporal, e ocorre pela formação do osso dentro do tecido conjuntivo primitivo com a presença de osteoblastos que produzem fibrilas de colágeno e glicoproteínas, e a deposição de cálcio forma a matriz do osso. A ossificação endocondral ocorre na maioria dos ossos longos, e são formados a partir de um tecido cartilaginoso pré-existente formado no embrião, centros de ossificação surgem dentro da cartilagem hialina, ocorre a vascularização em lacunas e as células osteoprogenitoras dão origem aos osteoblastos que depositarão a matriz óssea (15).

O crescimento longitudinal dos ossos longos ocorre através do disco ou placa epifisária, também chamada de placa de crescimento (Figura 3). As células que formam essa placa tomam forma distinta em camadas que representam estágios diferentes de formação do osso. A zona de repouso, onde há cartilagem, mas não há alteração. Os condrócitos mais distantes da diáfise formam a zona de proliferação, na qual os condrócitos se dividem e formam colunas paralelas no sentido longitudinal ao osso. A zona hipertrófica apresenta muitos condrócitos, a matriz fica reduzida e os condrócitos entram em apoptose. A zona de cartilagem calcificada, local onde ocorre a mineralização e termina a apoptose dos condrócitos. A zona de ossificação é onde surge o tecido ósseo, as células osteoprogenitoras se diferenciam em osteoblastos que depositam a matriz óssea $(15,22)$.

O osso é composto por material inorgânico depositado dentro da matriz orgânica composta por fibrilas de colágeno e glicoproteínas. Os minerais encontrados no osso incluem o cálcio, fósforo, magnésio, sódio, potássio, cloreto e fluoreto, e outros em quantidades mínimas. A estrutura geral do mineral ósseo é composta pelos cristais de hidroxiapatita pela fórmula $\mathrm{Ca}_{10}\left(\mathrm{PO}_{4}\right)_{6}(\mathrm{OH})_{2}$, sendo que para dez cátions cálcio são necessários seis ânions fosfato (15). 


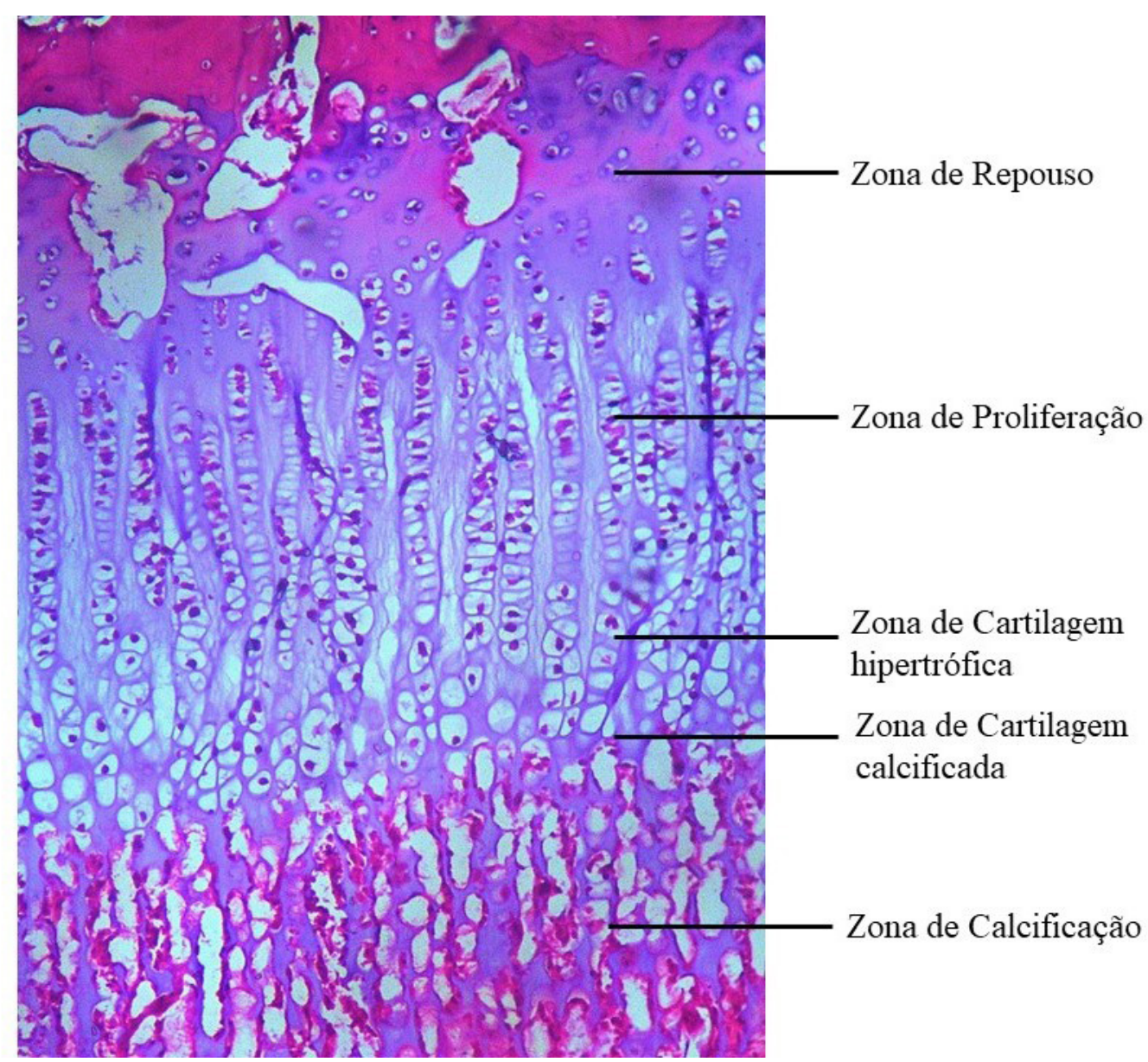

Figura 3. Fotomicrografia do disco epifisário, que mostra as cinco zonas e a formação do tecido ósseo(coloração eosina-hematoxilina, aumento 10x).

Fonte: Arquivo Pessoal.

A deposição do cálcio no tecido ósseo envolve a síntese de colágeno e fibrilas pelos osteoblastos para formar a matriz extracelular. A mobilização do cálcio é direcionada pelos osteoclastos que liberam proteínas e enzimas lisossomais que dissolvem osso e liberam a matriz orgânica (3).

A paratireoide apresenta um papel central na função fisiológica da vitamina D. Esta glândula é sensível ao nível sérico de cálcio, que quando é baixo aumenta a secreção de PTH na circulação. O PTH por sua vez, aumenta a atividade da enzima 1-hidroxilase e facilita a estimulação mediada pela $1,25(\mathrm{OH})_{2} \mathrm{D}_{3}$ tanto da atividade osteoclástica quanto da reabsorção renal de cálcio. (3).

A liberação do PTH tem relação direta com a concentração plasmática de cálcio, sendo que altos níveis de Ca ${ }^{2+}$ suprime a liberação do hormônio enquanto que baixas concentrações estimulam a sua liberação. As alterações nas concentrações de cálcio são detectadas por sensores de $\mathrm{Ca}^{2+}$ acoplados às proteínas $\mathrm{G}$, que estão localizadas sobre a membrana plasmática das células das paratireoides e nas células tubulares renais. Além disso, a 1,25(OH) $\mathrm{D}_{3}$ também contribui para a modulação dos níveis circulantes de PTH ao reduzir a transcrição genica deste hormônio (12).

A osteocondrose é uma doença em que ocorre uma lesão na placa de crescimento devido a uma falha na ossificação endocondral, onde a região afetada não calcifica, podendo ocorrer uma necrose visível histologicamente. Em suínos, as lesões da osteocondrose são mais comumente encontradas no úmero e no fêmur, mas também podem ocorrer nas articulações do ombro, quadril, ísquio, articulações vertebrais e nas junções costocondrais das costelas. Estas lesões podem ser observadas em análises histológicas de leitões com dois meses de idade, porém, estes animais só irão demonstrar a chamada "fraqueza das pernas" quando atingirem maior peso (24).

A remodelagem óssea é um processo de reabsorção, em que ocorre a remoção contínua de osso, seguida de uma nova matriz óssea e mineralização. A reabsorção óssea é realizada pelos osteoclastos e consiste em múltiplas etapas, que 
incluem o recrutamento e a diferenciação dos precursores dos osteoclastos em pré-osteoclastos (mononucleares), bem como a fusão destes pré-osteoclastos para formar osteoclastos multinucleados funcionais (12).

O osso é um tecido que está em constante renovação no organismo, em animais jovens a taxa de formação é maior que a taxa de reabsorção, pois há crescimento e formação dos ossos, já nos animais adultos há uma maior taxa de reabsorção tanto pelo controle da calcemia quanto pela remodelação dos ossos e no reparo de microfraturas devido a traumas (15).

Após o recrutamento, os osteoclastos são fixados a superfície do osso para iniciar a degradação óssea. A ligação do PTH aos osteoclastos desencadeia a síntese do ligante de osteoprotegerina (RANKL), uma proteína de membrana das células osteoblásticas. Este ligante se liga ao seu receptor, chamado de receptor ativador do fator nuclear kB (RANK) que é expresso nos precursores hematopoiéticos dos osteoclastos e estimula a diferenciação em osteoclastos funcionais. Estas duas proteínas de superfície celular, RANKL e RANK são reguladores essenciais para a formação e função dos osteoclastos (12).

A osteoprotegerina é uma proteína que pertence à família do receptor do fator de necrose tumoral (TNF), secretada pelos osteoblastos, que atua como antagonista natural do RANKL, impedindo sua ligação ao RANK, contribuindo com a regulação da reabsorção óssea, pois inibe a maturação dos osteoclastos mediada pelo RANKL (12).

Para que ocorra a reabsorção óssea os osteclastos são fixados à superfície celular por proteínas, denominadas $\beta$-integrinas, formando um ambiente isolado entre osteoclasto e a superfície óssea. Neste ambiente ocorre uma acidificação mediada por $\mathrm{H}^{+}$-ATPases, os íons hidrogênio gerados pela anidrase carbônica II são liberados para dissolver o mineral ósseo. A redução no pH deste ambiente favorece a dissolução da hidroxiapatita e propicia condições adequadas para a ação das proteínas lisossomais secretadas pelos osteoclastos. Os produtos da reabsorção óssea são transportados por endocitose pelo osteoclasto e liberados na superfície antirreabsortiva por meio de um processo de transcitose (trânsito através da célula) indo para a circulação sistêmica (12).

0 osso também pode ser um local para o armazenamento da vitamina $\mathrm{D}$, porém o perfil de metabolitos difere do intestino, e apresenta muito mais a forma $25(\mathrm{OH}) \mathrm{D}_{3}$, cerca de $50 \%$, e menos $1,25(\mathrm{OH})_{2} \mathrm{D}_{3}$, menos de $35 \%$. A forma $24,25(\mathrm{OH})_{2} \mathrm{D}_{3}$ também está presente, em níveis semelhantes ao da $25(\mathrm{OH}) \mathrm{D}_{3}(3)$.

\section{CONSIDERAÇÕES FINAIS}

Diante do exposto, fica claro a importância da vitamina D na alimentação de suínos, desde a formação e desenvolvimento dos ossos até a regulação mineral de cálcio e fósforo. Por isso, se torna uma vitamina essencial à saúde dos animais. Atualmente existem várias formas no mercado, como a $25(\mathrm{OH}) \mathrm{D}_{3}$ e a $1,25(\mathrm{OH})_{2} \mathrm{D}_{3}$, além do já conhecido colecalciferol. Entretanto, mais pesquisas são necessárias para avaliar as formas ativas na nutrição de suínos.

\section{Conflito de interesse}

Não há.

\section{REFERÊNCIAS}

1. Castro LCG. O sistema endocrinológico vitamina D. Arq Bras Endocrinol Metab. 2011; 55(8):566-575. D0I: http:// dx.doi.org/10.1590/S0004-27302011000800010

2. Hollis BW. Circulating 25-hydroxyvitamin D levels indicative of vitamin D sufficiency: implications for estabilishing a new effective dietary intake recommendation for vitamin D. J Nutr. 2005; (135):317-322. DOI: https://doi. org/10.1093/jn/135.2.317

3. Combs Jr, G.F. The vitamins: fundamental aspects in nutrition and health. 3ํㅡㄹ Edição. London: Elsevier Academic Press. 2008.

4. Hill, M.A.Causes of degenerativejointdisease(osteoarthrosis) and dyschondroplasia (osteochondrosis) in pigs. JAm Vet Med Assoc, 1990; 197(1):107-113. Disponível em: https://www.ncbi.nlm.nih.gov/pubmed/2196249?dopt=Abstract

5. Jorgensen, B.; Andersen, S. Genetic parameters for osteochondrosis in Danish landrace and Yorkshire boars and correlations with leg weakness and production traits. J Anim Sci, 2000; 71(3):427-434. DOI: https://doi. org/10.1017/S1357729800055442 
6. Regassa, A.; Adhikari, R.; Nyachoti, C.M.; Kim, W.K. Effects of 25-(OH) $\mathrm{D}_{3}$ on fecal Ca and P excretion, boné mineralization, $\mathrm{Ca}$ and $\mathrm{P}$ transporter mRNA expression. And performance in growing female pigs. J Environ Sci Health, 2015; 50:293-299. DOI: https://doi.org/10.1080/03601234.2015.999612

7. Holick, M.F. Vitamin D deficiency. N Engl J Med, 2007; 357:266-281. DOI: https://doi.org/10.1056/NEJMra070553

8. Deluca, H.F.; Cantorna, M.T. Vitamin D: its role and uses in immunology. The FASEB Journal, 2001; 15(14):25792585. DOI: https://doi.org/10.1096/fj.01-0433rev

9. Harper, R.A. Bioquímica Ilustrada. 5aㅡ Edição, Porto Alegre: Artmed. 2012.

10. Norman, A.W. From vitamin D to hormone D: fundamentals os the vitamin D endocrine system essential for good health. Am J Clin Nut, 2008; 88(2):491-499. DOI: https://doi.org/10.1093/ajcn/88.2.491S

11. Alexander, B.M.; Ingold, B.C.; Young, J.L.; Fensterseifer, P.J.; Wechsler, P.J;; Austin, K.J.; et al. Sunlight exposure increases vitamin D sufficiency in growing pigs fed a diet formulated to exceed requirements. Domest Anim Endocrinol, 2017; (59):37-42. DOI: https://doi.org/10.1016/i.domaniend.2016.10.006

12. Molina, P.E.; Fisiologia Endócrina. 4a Edição, Porto Alegre: AMGH. 2014.

13. Schröder, B.; Breves, G. Mechanisms and regulation of calcium absorption from the gastrointestinal tract in pigs and ruminants: comparative aspects with special emphasis on hypocalcemia in dairy cows. Anim Health Res Rev, 2006; 7(1):31-41. DOI: https://doi.org/10.1017/S1466252307001144

14. Jefferies, D.; Farquharson, C.; Thomson, J.; Smith, W.; Seawright, E.; Mccormack, H.; et al. Differences in metabolic parameters and gene expression related to osteochondrosis/osteoarthrosis in pigs fed 25-hydroxyvitamin D3. Vet Res, 2002; 33(4):383-396. DOI: https://doi.org/10.1051/vetres:2002024

15. Dukes, H.H.; Reece, W.O. Fisiologia dos animais domésticos. 12ª edição. Rio de Janeiro: Guanabara Koogan; 2015.

16. Schlegel, P.; Gutzwiller, A. Effet du glycoside de 1,25-dihydroxyvitamine D3 dans un alimente carencé ou non en phosphore, sur les performances de croissance et le statut mineral de porcelets. Journées Rech Procine, 2015; 47:123-124. Disponível em: http://www.journees-recherche-porcine.com/texte/2015/alimentation/16AP.pdf

17. Speeckaert, M.; Huang, G.; Delanhe, J.R.; Taes, Y.E.C. Biological and clinical aspects of the vitamin D binding protein (Gc-globulin) and its polymorphism. Clin Chim Acta, 2006; 372(1):33-42. DOI: https://doi.org/10.1016/j. cca.2006.03.011

18. Feldman, D. Vitamin D: Volume 1: Biochemistry, physiology and diagnostics, 4를 Edição, London: Elsevier Academic Press. 2018.

19. Blomberg, M.J.; Nielsen, J.E.; Jorgensen, A.; Rajpert, E.M.; Kristensen, D.M.; Jorgensen N.; et al. Vitamin D receptor and vitamin D metabolizing enzymes are expressed in the humam male reproductive tract. Hum Rep, 2010; 25(5):13031311. DOI: https://doi.org/10.1093/humrep/deq024

20. Holick, M.F. High Prevalence of Vitamin D inadequacy and implications for health. Mayo Clinic Proc, 2006; 81(3):353373. DOI: https://doi.org/10.4065/81.3.353

21. Rochel, N.; Wurtz, J.M.; Mitschler, A.; Klaholz, B.; Moras, D. The Crystal structure of the nuclear receptor for vitamin D bound to its natural ligand. Mol Cell, 2000; 5(1):173-179. DOI: https://doi.org/10.1016/S1097-2765(00)80413-X

22. Junqueira, L.C.; Carneiro, J. Histologia básica - texto e atlas. 12ª Ed. Rio de Janeiro: Guanabara Koogan. 2013.

23. Naja, R.P.; Dardenne, O.; Arabian, A.; St Arnaud, R. Chondrocyte-specific modulation of Cyp27b1 expression supports a role for local synthesis of 1,25-dihydroxyvitamin D3 in growth plate development. Endocrinology, 2009; 150(9):4024-4032. DOI: https://doi.org/10.1210/en.2008-1410

24. Ytrehus, B.; Carlson, C.S.; Ekman, S. Etiology and pathogenesis of osteochondrosis. Vet Pathol, 2007; (44):429-448. DOI: https://doi.org/10.1354/vp.44-4-429 